\title{
Nonpremixed Flamelet Statistics at Flame Base of Lifted Turbulent Jet Nonpremixed Flames*
}

\author{
Susumu NODA**, Hisaya MORI ${ }^{* * *}$, Yusuke HONGO*** and Makoto NISHIOKA***
}

\begin{abstract}
Nonpremixed flamelet statistics at the flame base of lifted turbulent nonpremixed flames are investigated experimentally using a planar temperature Rayleigh scattering method. A methane/hydrogen mixture is supplied from a tube of $3.2 \mathrm{~mm}$ I.D. into the surrounding air flow so as to form two lifted turbulent nonpremixed flames having exit velocities of $50 \mathrm{~m} / \mathrm{s}$ $(R e=4200)$ and $80 \mathrm{~m} / \mathrm{s}(R e=6700)$, respectively. Temperature data are related to maximum temperature at several flame positions based on the instantaneous flame base tip as containing information on the reaction region of each nonpremixed flamelet at each position. The statistics in terms of maximum temperature, thermal dissipation rate, scalar dissipation rate, and flame brush are discussed with reference to the modeling of the flame base structure. The scalar dissipation rate has log-normal statistics and the quenching scalar dissipation rate is lower than the critical value predicted using the uniformly strained counter nonpremixed flame. These statistics are compared to those obtained using a model proposed by Müller et al. ${ }^{(1)}$, which combines the flamelet model and the scalar field variable to predict lifted turbulent nonpremixed flames. The comparison has shown that the model can qualitatively predict lifted turbulent nonpremixed flames, but modification is required in order to obtain more accurate quantitative prediction taking into account the edge flame structure, the statistics of scalar dissipation rate, and the statistics of flame brush.
\end{abstract}

Key Words: Combustion, Turbulent Combustion, Nonpremixed Flame, Lifted Flame, Flamelet Model, Laser Diagnostics

\section{Introduction}

Lifted turbulent nonpremixed flames have received considerable attention, and many studies of flame stability, including the pioneering study by Vanquickenbone and Van Tiggelen ${ }^{(2)}$, have been performed. Pitts ${ }^{(3)}$ reviewed important theories proposed in terms of the flame stabilization mechanism. The problem of whether flame stability is determined by flame stretch ${ }^{(4)}$ or the balance between premixed turbulent burning velocity and average flow velocity ${ }^{(5),(6)}$ remains unclear. Recent laser measurements may have revealed the existence of each triple flame, consisting of a nonpremixed flame, a rich premixed flame, and a lean premixed flame at the bases of lifted tur-

* Received 12th May, 2004 (No. 04-4121)

** Department of Mechanical Engineering, Toyohashi University of Technology, 1-1 Hibarigaoka, Tempaku, Toyohashi 441-8580, Japan. E-mail: noda@ mech.tut.ac.jp

*** Graduate student, Department of Mechanical Engineering, Toyohashi University of Technology, 1-1 Hibarigaoka, Tempaku, Toyohashi 441-8580, Japan bulent nonpremixed flames ${ }^{(7)-(9)}$, providing evidence that lifted turbulent nonpremixed flames have the characteristics of premixed combustion, such as flame propagation at the flame base. The bases of lifted turbulent nonpremixed flames are now thought to be subject to both flame stretch and partial premixing. Here, the term "partial premixing" is used to denote that fuel mixes partially with an oxidizer (air) in the proximal region between the nozzle rim and the flame base.

Lifted turbulent nonpremixed flames are also interesting from the viewpoint of NOx reduction, which was confirmed on a laboratory scale ${ }^{(10)}$. Similar phenomena had been observed in lifted turbulent nonpremixed flames formed in high-temperature coflowing air $^{(11),(12)}$. Such a reduction phenomenon should be strongly associated with the partial premixing. To put the reduction phenomenon to good use, the flame base structure should be clarified. Unlike rim-stabilized turbulent nonpremixed flames, however, this phenomenon includes new and complicated problems, such as transient processes from unburned to burned structures and from the premixed/partial premixed 
combustion to the nonpremixed combustion. As a first step toward the clarification of the flamelet structure at the bases of lifted turbulent nonpremixed flames, we focus on the statistics of nonpremixed flamelet in terms of maximum temperature, thermal dissipation rate, scalar dissipation rate, and flame brush that are useful in the modeling of lifted turbulent nonpremixed flames. Temperature data measured by a planar Rayleigh scattering method are discussed in relation to maximum temperature at several flame positions based on the instantaneous flame base tip containing information on the reaction region of each nonpremixed flamelet at each position. The flamelet statistics on the basis of each flamelet at the base to our knowledge have never been experimentally clarified. These statistics have also been compared to a model proposed by Müller et al. ${ }^{(1)}$, which combines the flamelet model and the scalar field variable to predict lifted turbulent nonpremixed flames.

\section{Experimental Apparatus and Methods}

\subsection{Burner description and flow conditions}

Experiments were conducted in a coflow configuration. The burner consisted of a fuel pipe of $d=3.2 \mathrm{~mm}$ I.D. (0.2 mm lip thickness) located at the center and a concentric air tube. The fuel was composed of a mixture of $38 \%$ methane and $62 \%$ hydrogen by volume, which was developed by Dibble and Hollenbach for determining the constant Rayleigh cross section and has an error of approximately $5 \%$ before and after reaction ${ }^{(13),(14)}$. The bulk fuel exit velocities were $50 \mathrm{~m} / \mathrm{s}(R e=4200)$ and $80 \mathrm{~m} / \mathrm{s}(R e=6700)$; hereafter referred to as cases 1 and 2 , respectively. Fuel jets were surrounded by a slow and room-temperature air coflow of $1 \mathrm{~m} / \mathrm{s}$. The surrounding air was filtered to remove particles larger than $3 \mu \mathrm{m}$ for the Rayleigh scattering system to prevent interference due to Mie scattering.

\subsection{Planar temperature Rayleigh imaging system}

Nonpremixed flamelets at bases of lifted turbulent nonpremixed flames are investigated using a planar temperature Rayleigh imaging system. A pulsed Nd:YAG laser (Spectra-Physics GCR-170) was used to generate single-shot energies of $450 \mathrm{~mJ} /$ pulse at a wavelength of $532 \mathrm{~nm}$. The beam was converged into a 0.9-cm-high laser light sheet using a cylindrical lens having a focal length of $1000 \mathrm{~mm}$. The maximum thickness of the sheet was $0.2 \mathrm{~mm}$ in the image. Rayleigh scattering light was imaged using an intensified charge-coupled device (ICCD) camera (Hamamatsu Photonics C5909) having F/1.8 collection optics. The ICCD camera has $768 \times 493$ pixels and yields 0.08 -mm spacing between pixels in the present experiment. A 5-nm band-pass width, 532-nm centered interference filter was used to reject luminosity. A gating with a short gate width of $40 \mathrm{~ns}$ was used to reduce noise. In the present system, the effect of chemiluminescence was negligible because no noticeable light was emitted from the flame without the laser shot relative to Rayleigh scattering light. To refine signals involving noises such as thermal noise through intensification, the obtained images were processed using a median filter of $5 \times 5$ pixels to suppress errors of up to $4.5 \%$ at room temperature. The signal-to-noise ratio of the ICCD camera is proportional to the square root of the light intensity received. The increase in temperature in flames decreases Rayleigh scattering light intensity and degrades the $s / n$ ratio. In the present study, however, this is not considered. Scattering light from helium gas was also measured as background noise ${ }^{(14)}$. The ratio of scattering light from the helium gas to scattering light from air was evaluated to be $10 \%$. This noise was removed at the first stage of image processing. The spatial resolution of the system was $0.4 \mathrm{~mm}$ after the median filter process, matching $2.1-2.5 \eta$. Here, $\eta$ is the Kolmogorov scale and the estimates are obtained in cold flows at the bases of the lifted flames reported here (at $x / d=10$ for case 1 , and at $x / d=17.2$ for case 2 , respectively, as described later). The Kolmogorov scale is expected to have larger values due to heat release by the flames. Namazian et al. ${ }^{(15)}$ reported that a spatial resolution of $5 \eta$ should be sufficient for capturing $60 \%$ of the scalar dissipation rate. The present resolution consequently should be sufficient to record the thermal dissipation rate, which is transformed to the scalar dissipation rate under some assumptions described later.

Under the assumption of a constant pressure for the present low-Mach-number flows, the temperature $T$ is inversely proportional to Rayleigh scattering light intensity after the subtraction of the background noise $I_{R}$ as

$$
T=T_{0} \frac{I_{R, 0}}{I_{R}},
$$

where the subscript 0 indicates a reference value, for example, that of the surrounding air, in the present study.

\subsection{Evaluation of scalar dissipation rate}

Information on the scalar dissipation rate reflecting flame stretch is essential for evaluating of the structure of the nonpremixed flamelet. The two-dimensional temperature distribution obtained is related to the scalar dissipation rate $\chi$ through the thermal dissipation rate $\chi_{T}$ under the assumptions of a Lewis number of unity and temperature being a function of only mixture fraction ${ }^{(16)}$. Here, the differential diffusion effect attributable to the mixed fuel of methane and hydrogen is ignored due to short residence time of the fuel determined on the basis of liftoff height for the present cases, being evaluated as approximately $t_{\text {res }}=6.6 \times 10^{-4} \mathrm{~s}$. Since the diffusion coefficients of methane and hydrogen to air are $D_{\mathrm{CH}_{4}}=0.229 \mathrm{~cm}^{2} / \mathrm{s}$ and $D_{\mathrm{H}_{2}}=0.787 \mathrm{~cm}^{2} / \mathrm{s}$ in cold flow, respectively, the difference between the characteristic diffusion distances $\Delta l$ is evaluated on the basis of $\left(D t_{r e s}\right)^{1 / 2}$ as approximately $0.1 \mathrm{~mm}$, being comparable to the present pixel spacing. 
The other estimation must be based on the diffusion distance $-D(d Y / d r) \cdot t_{\text {res }}$ in consideration of the change in concentration gradient induced by turbulence; here, $D$ and $(d Y / d r)$ are the diffusion coefficient and radial concentration gradient, respectively. Although the concentration gradient data in the cold flows of the present lifted flames are not available, the following estimation on the data of Watson et al. ${ }^{(17)}$, who examined cold flows at the bases of lifted methane nonpremixed flames using a simultaneous CH-PLIF and Rayleigh scattering system, may be instructive. Their experimental conditions named cases 1 and 2 are close to the present conditions in terms of exit Reynolds number, but their fuel is methane and fuel nozzle diameter is $5 \mathrm{~mm}$. The exit velocities are $15.8 \mathrm{~m} / \mathrm{s}$ for case 1 and $21.2 \mathrm{~m} / \mathrm{s}$ for case 2 . We now use the maximum scalar dissipation rates of $\chi_{\max }=22.91 \mathrm{~s}^{-1}$ and $12.57 \mathrm{~s}^{-1}$ in the cold flows of both of their cases to estimate the difference in diffusion distance on the basis of the differential diffusion effect of the present fuel. Under the assumption of the axial mixture fraction gradient $(\partial Z / \partial x)$ being smaller than the radial mixture fraction gradient $(\partial Z / \partial r)$, the maximum concentration gradient $(\partial Y / \partial r)_{\max }$ is approximated as

$$
(\partial Y / \partial r)_{\max }=\left(\chi_{\max } / 4 D\right)^{1 / 2} .
$$

Here, the identity between the mixture fraction and the fuel mass fraction in the cold flow is used. The estimation gives approximately $\Delta l=5.6 \times 10^{-3} \mathrm{~mm}$. Even though $10 \chi_{\max }$ as the maximum scalar dissipation rate is used in consideration of the exit velocity difference between Watson et al. and the present study, the difference is approximately $1.7 \times 10^{-2} \mathrm{~mm}$, being again comparable to the present pixel spacing.

Radiation heat loss may also become cause of error. This heat loss is however ignored due to the negligible radiant fractions of the present cases being only approximately $5.5 \times 10^{-3}$. The radiant fraction $\varepsilon_{\text {rad }}$ is evaluated according to Turns ${ }^{(18)}$ as

$$
\varepsilon_{\text {rad }}=\dot{Q}_{\text {rad }} /\left(\dot{m}_{F} \Delta h_{c}\right)
$$

where $\dot{Q}_{\text {rad }}$ is the radiant heat-transfer rate from the flame, $\dot{m}_{F} \Delta h_{c}$ the total heat released by the flame, $\dot{m}_{F}$ the mass flow rate of the fuel and $\Delta h_{c}$ the fuel heat of combustion, respectively. The flame is considered to be a uniform heat source for both heat release and radiation. The total heat release rates $\dot{m}_{F} \Delta h_{c}$ are evaluated to be $2.9 \mathrm{~kJ} / \mathrm{s}$ for case 1 and $4.6 \mathrm{~kJ} / \mathrm{s}$ for case 2 , respectively. The radiant heattransfer rate $\dot{Q}_{\text {rad }}$ is furthermore approximated as

$$
\dot{Q}_{\text {rad }} \approx a_{p} V_{f} \sigma_{B} T_{f}^{4},
$$

where $a_{p}$ is an appropriate absorption coefficient for the flame, $V_{f}$ the flame volume, $\sigma_{B}$ the Stefan-Boltzmann constant, and $T_{f}$ the flame temperature. The StefanBoltzmann constant is $\sigma_{B}=5.67 \times 10^{-11}\left[\mathrm{~kJ} \cdot \mathrm{s}^{-1} \cdot \mathrm{m}^{-2} \cdot \mathrm{K}^{-4}\right]$. Furthermore, for the estimation of a larger radiant fraction, the following data were used; $a_{p}=1, V_{f}=(10 d)^{3} \times$ $10^{-9}\left[\mathrm{~m}^{3}\right], T_{f}=1800 \mathrm{~K}$.
The thermal dissipation rate $\chi_{T}$ is defined as

$$
\chi_{T}=2 \alpha(\nabla T)^{2},
$$

where $\alpha$ is the thermal conductivity. The rate $\chi_{T}$ is evaluated on the basis of that reported by Everest et al. ${ }^{(16)}$, namely,

$$
\alpha=\left(0.20 \mathrm{~cm}^{2} / \mathrm{s}\right)(T / 300 \mathrm{~K})^{1.8} .
$$

$\chi_{T}$ at each pixel position $(i, j)$ is evaluated as

$$
\begin{aligned}
\chi_{T, i j} & =2 \alpha_{i, j}\left\{\left[\left(T_{i+5, j}-T_{i-5, j}\right) /(20 h)\right.\right. \\
& +\left(T_{i+5, j-5}-T_{i-5, j+5}\right) /(40 h) \\
& \left.+\left(T_{i+5, j+5}-T_{i-5, j-5}\right) /(40 h)\right]^{2} \\
& +2\left[\left(T_{i, j+5}-T_{i, j-5}\right) /(20 h)\right. \\
& +\left(T_{i+5, j+5}-T_{i-5, j-5}\right) /(40 h) \\
& \left.\left.+\left(T_{i-5, j+5}-T_{i+5, j-5}\right) /(40 h)\right]^{2}\right\} .
\end{aligned}
$$

Here, the central differentiation algorithm is used and $h$ is the pixel spacing. The azimuthal term is handled as being equal to the radial term. Equation (7) is corrected from the corresponding equation of Everest et al. with misprints.

The scalar dissipation rate $\chi$ is

$$
\chi=2 D(\nabla Z)^{2},
$$

where $Z$ is the mixture fraction and $D$ is the diffusion coefficient. Thus, the scalar dissipation rate is re-expressed as a function of thermal dissipation rate and temperature gradient with respect to the mixture fraction as ${ }^{(16)}$

$$
\chi=\chi_{T} /(d T / d Z)^{2} .
$$

For the investigation of the nonpremixed flamelet, scalar dissipation rate at stoichiometry $\chi_{s t}$ should be evaluated. For the near-equilibrium assumption, $d T / d Z$ at stoichiometry must be represented by the corresponding value at the maximum temperature $T_{\max }$. We have thus approximated $d T / d Z$ as the arithmetic mean of the gradients $\left(T_{\max }-T_{0}\right) / Z_{s t}$ on the lean side and $\left(T_{0}-T_{\max }\right) /\left(1-Z_{s t}\right)$ on the rich side on the basis of the nonpremixed flame structure. Here, $Z_{s t}$ is the stoichiometric mixture fraction. This approximation for the rich side may lead to an overestimation, because the temperature gradient with respect to the mixture fraction on the rich side near stoichiometry has a steeper negative slope ${ }^{(19)}$. Moreover, if the triple flame attributable to the partial premixing in the proximal region is considered, the present approximation may also overestimate $d T / d Z$, because the triple flame decreases the temperature gradient at stoichiometry. Nevertheless, considering a small $Z_{s t}$ of 0.048 for the present fuel as well as the lower flame temperature at the bases of lifted flames, the above approximation is used for the evaluation of $d T / d Z$.

To evaluate the structure of the nonpremixed flamelet, only data based on the maximum temperature are used in the following discussion. These data are collected for four flame positions; (a) the instantaneous flame base tip of a lifted flame, (b) $1.6 \mathrm{~mm}$ downstream of the tip, (c) $3.2 \mathrm{~mm}$ 

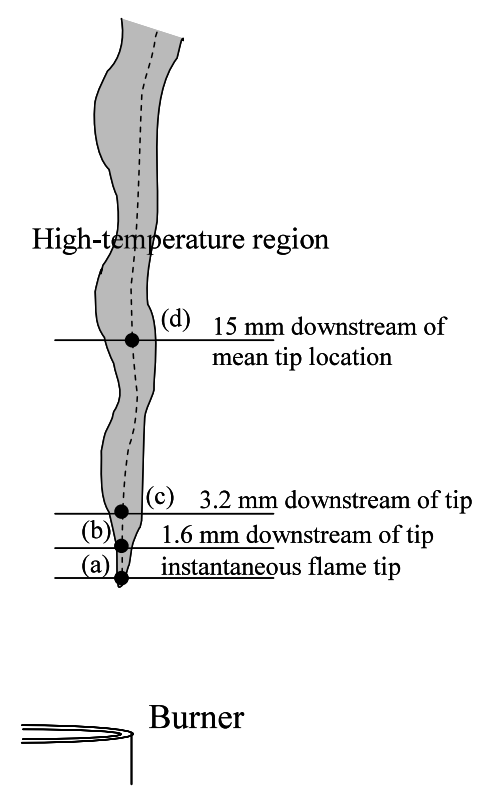

Fig. 1 Schematic diagram of measurement locations. The dashed line denotes the maximum temperature ridgeline. Positions (a), (b), and (c) are located on the ridgeline of each flamelet and are not fixed spatially.

downstream of the tip, and (d) $15 \mathrm{~mm}$ downstream of the mean tip location shown in Fig. 1. Hence, positions (a), (b), and (c) are on each flamelet, and are not fixed spatially. Here, the tip is determined as a position $0.16 \mathrm{~mm}$ ( 2 pixels) downstream of the location where the Rayleigh scattering intensity has decreased approximately by $9 \%$ from its value in the cold flow. This corresponds to a temperature increase of approximately $30 \mathrm{~K}$. Data at position (d) include the variation in temperature caused by the flame movement, because the tip of the lifted flame is not specified at the position over one laser sheet width. Consequently, the data acquired at position (d) are used as reference data. Two-hundred data are collected for the statistics at each position.

\section{Results and Discussion}

Lifted turbulent jet nonpremixed flames were visualized by the Schlieren method and the planar temperature Rayleigh scattering method, as shown in Figs. 2 and 3. The mean liftoff heights are approximately $x=32 \mathrm{~mm}$ $(x / d=10)$ for case 1 and $x=55 \mathrm{~mm}(x / d=17.2)$ for case 2. The fuel jets collide with the flame bases of the lifted flames and produce small-scale turbulence, compared with turbulence downstream, dominating the flame bases, as shown in Fig. 2. The increase in exit velocity lifts the flame up and increases flame width. From the 2D temperature distributions, flamelets tend to be deformed strongly by the turbulence induced by the increase in exit velocity.

\subsection{Maximum temperature probability density functions}

The maximum temperature data were collected at

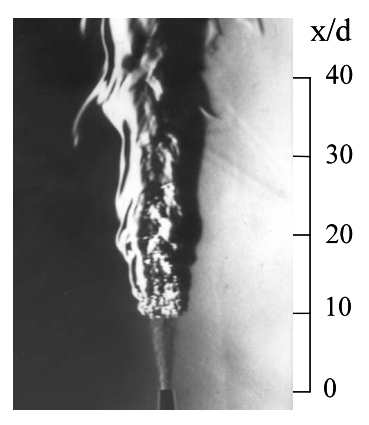

(I) Case 1

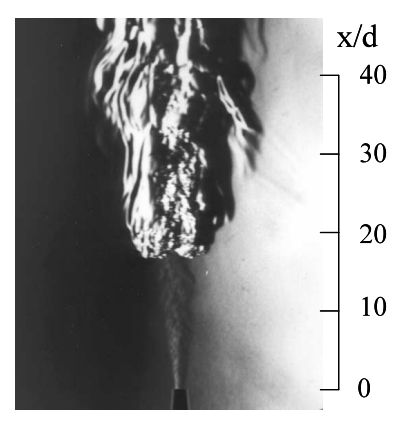

(II) Case 2
Fig. 2 Schlieren photographs of lifted flames

(I) Case 1

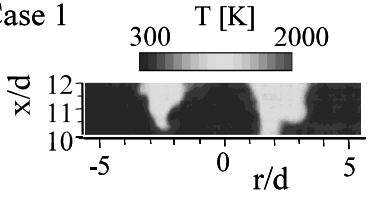

(II) Case $2 \quad 300 \quad \mathrm{~T}[\mathrm{~K}] \quad 1500$

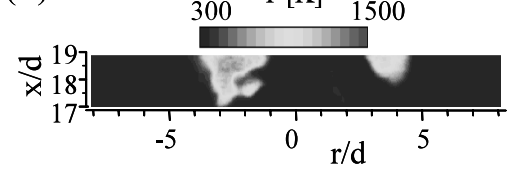

Fig. 3 Planar temperature distributions

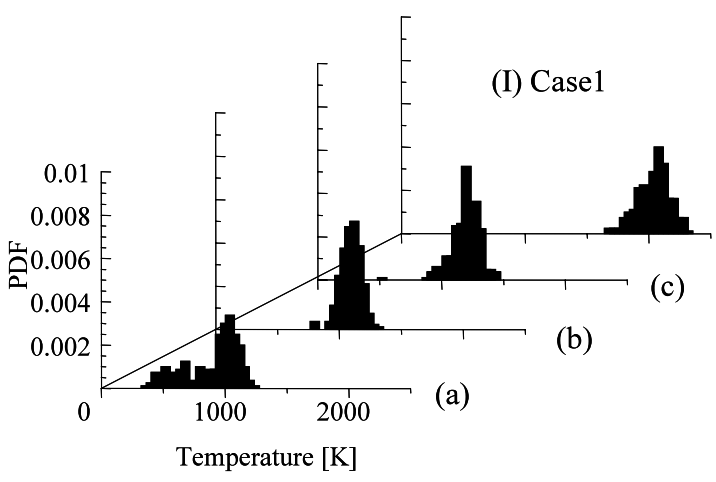

(d)

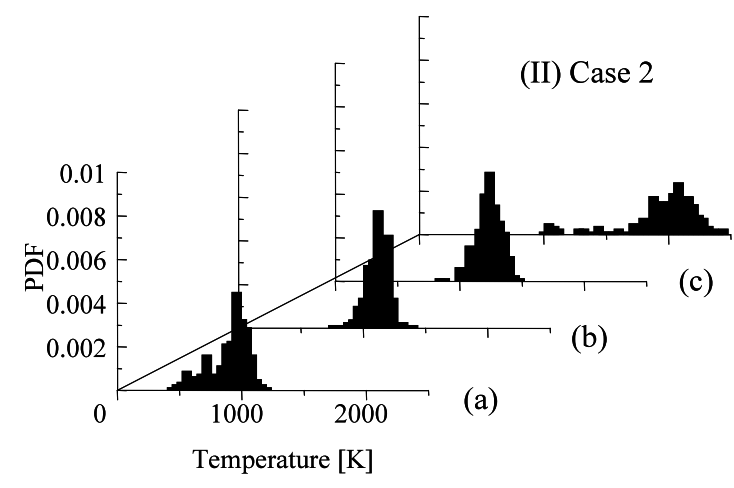

(d)

each position and used to generate probability density functions (pdfs), as shown in Fig. 4. The maximum temperature should be related to the progress variable by normalization in terms of the fully burned and frozen val- 
ues ${ }^{(20)}$. Although the chemistry of the present fuel is not elucidated, laminar tubular calculations by Yamamoto and Onuma $^{(21)}$ did not show that the combustion of a mixture of methane and hydrogen generates two flames, as indicated by two temperature peaks attributable to the two fuels. Therefore, the maximum temperature position is considered as the center of the reaction. For both cases, pdfs at positions (a), (b), and (c) are very similar. At flame tip position (a), a high probability exists at approximately $1000 \mathrm{~K}$, whereas a flat and low probability exists in the range from room temperature, $300 \mathrm{~K}$, to $750 \mathrm{~K}$, corresponding to the temperature in the frozen reaction region where the reaction does not proceed and the temperature is markedly decreased from that in the rear reaction region ${ }^{(22)}$. The high probability at approximately $1000 \mathrm{~K}$ should be due to the reaction region, because the profiles are similar to the pdf profiles of positions (b) and (c), showing near-Gaussian profiles. Near-Gaussian pdfs may indicate that flamelets at the flame base are subject to homogeneous turbulence in the cold jet. Therefore, a large degree of signal processing should lead to the Gaussian statistics of temperature, as predicted by the central limit theorem. The mean flame temperature at position (a) tends to decrease slightly to $990 \mathrm{~K}$ from $1050 \mathrm{~K}$ with the exit velocity, and tends to increase by approximately $40 \mathrm{~K}$ at positions (b) and (c). The temperature rms values are evaluated as approximately $120 \mathrm{~K}$ at the three positions for both cases, without the data of the frozen reaction region. Although the slight decrease in the mean flame temperature at position (a) may be caused by the increase in turbulence intensity reflecting the flame stretch effect, a comparison between these cases does not reveal any notable difference. This similarity may imply that lifted nonpremixed flames are anchored under proper conditions for stabilization, even though the jet exit velocity is changed. The mean maximum temperature at position (d) increases to approximately $2000 \mathrm{~K}$.

\subsection{Joint probability density functions of max- imum temperature and thermal dissipation rate}

Figures 5 and 6 show the joint probability density functions (jpdfs) of the maximum temperature and thermal dissipation rate at each position. These jpdfs indicate statistics before the scalar dissipation rate obtained through the approximations mentioned above. By definition, thermal dissipation rate increases with temperature gradient; more generally, the decrease in flame temperature leads to a decrease in thermal dissipation rate. This is in contrast to the phenomenon whereby the increase in scalar dissipation rate decreases flame temperature ${ }^{(23)}$.

The jpdfs at positions (a), (b), and (c) are again very similar for both cases. The jpdf profiles at position (a) are near-Gaussian upon the elimination of the data of the frozen reaction region, whereas the jpdf profiles
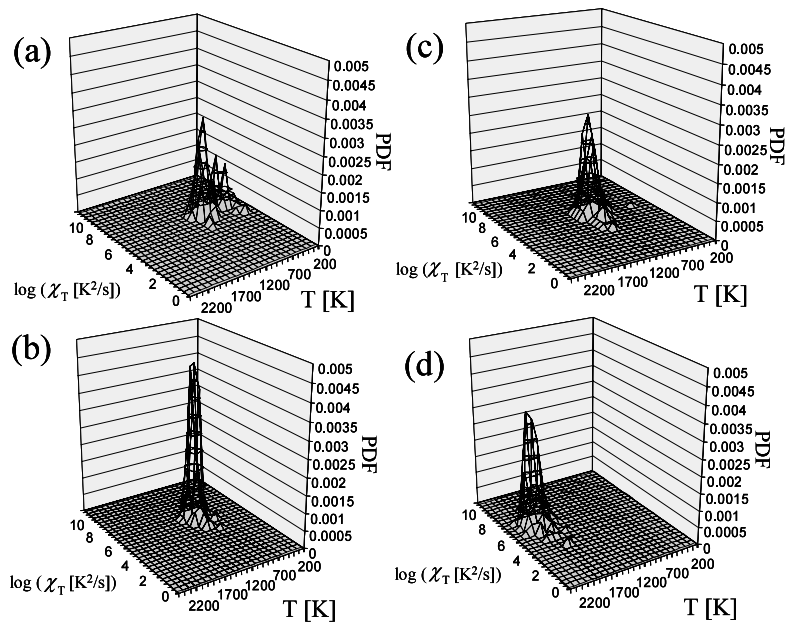

Fig. 5 Joint pdfs of maximum temperature and thermal dissipation rate (case 1)
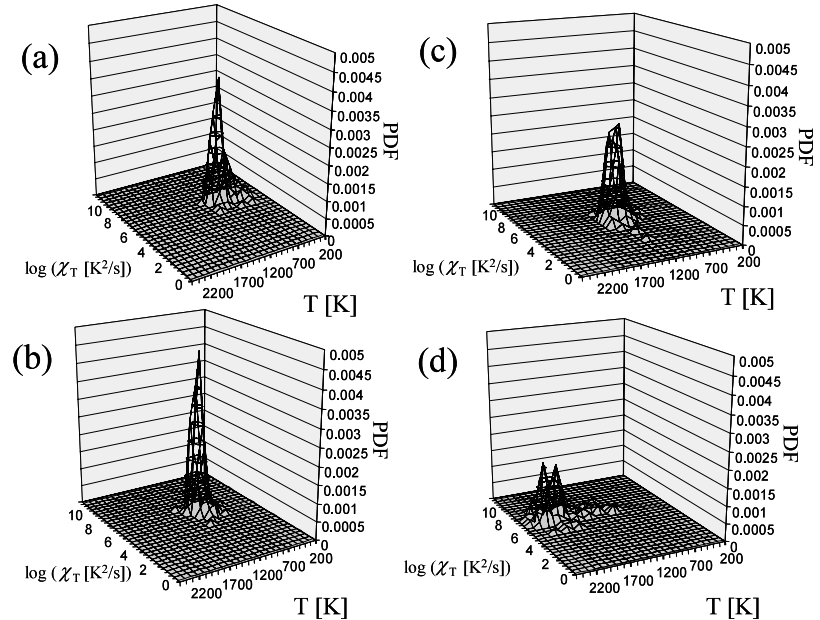

Fig. 6 Joint pdfs of maximum temperature and thermal dissipation rate (case 2)

downstream of the flame tip tend to spread to a lower thermal dissipation rate reflecting the increase in flame width. Note that the mean thermal dissipation rate increases slightly at position (a) as exit velocity increases (case 2), together with the decrease in maximum temperature mentioned above.

\subsection{Pdfs of scalar dissipation rate}

Figure 7 shows the pdfs of scalar dissipation rate conditional on maximum temperature. Although the pdfs of scalar dissipation rate contain the same information as the jpdfs of thermal dissipation rate and maximum temperature, the statistics of scalar dissipation rate are more important for the modeling of turbulent nonpremixed flames.

The profiles of pdfs of both cases closely resemble each other, but are slightly different at position (a). For pdfs at position (a) for both cases, an increase in probability of approximately $\ln \chi=-0.5$ is attributable to the low temperature in the frozen reaction region. With the elimination of the data of the frozen reaction region, the pdfs 

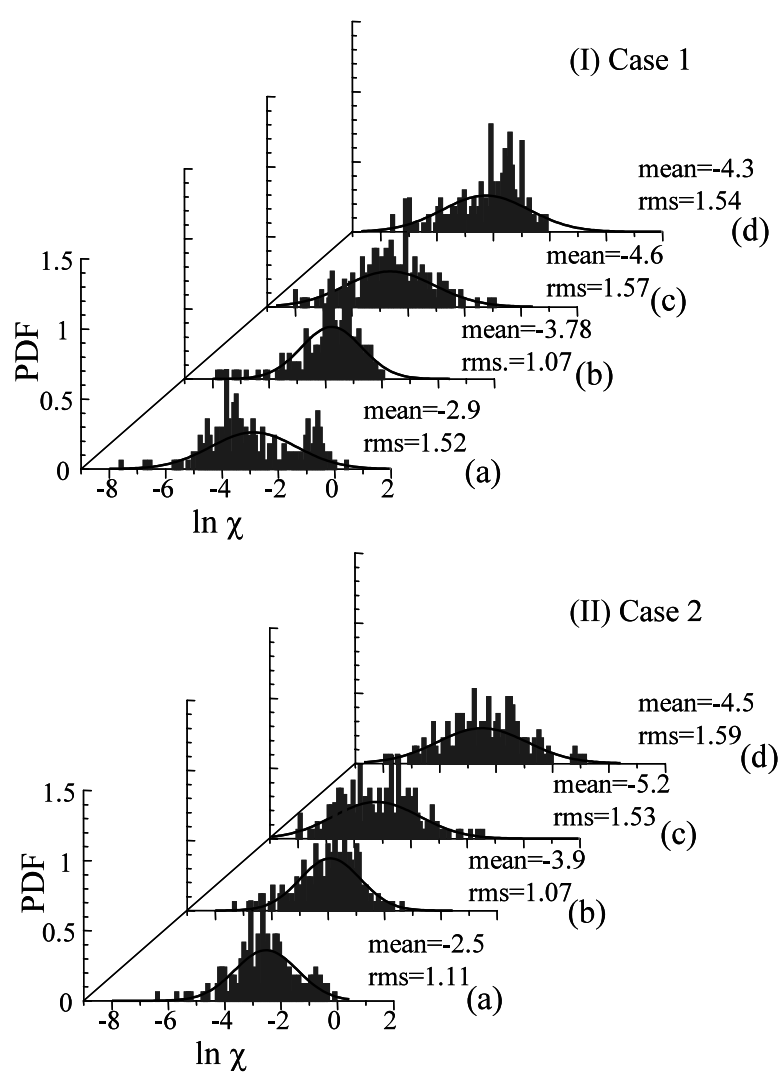

Fig. 7 Pdfs of scalar dissipation rate conditional on maximum temperature. Solid lines denote log-normal profiles.

at each position may admit the log-normal approximation indicated by solid lines in the figures. This indicates that the statistics of the scalar dissipation rate at the base of turbulent lifted nonpremixed flames are not strongly affected by partial premixing in the proximal region. The quenching scalar dissipation rate $\chi_{q}$ of the present fuel diluted to $70 \%$ by volume with nitrogen in a counterflow configuration formed by a Tsuji burner is $17.2 \mathrm{~s}^{-1}$, yielding $\ln \chi_{q}=$ $2.84^{(24)}$. Here, the present fuel did not allow the measurement of quenching scalar dissipation rate in the counterflow configuration, because the flame was deformed like a cellular flame when fuel flow velocity increased to prevent the quenching effect of the burner. The present results are distributed at much less than $\chi_{q}$ of the present fuel, which is anticipated to have a larger value than above. The low scalar dissipation rate at position (a) as the flame tip is important because the flamelet model requires the extinction of the flamelet under a flame stretch condition of more than $\chi_{q}$. In other words, flamelets survive only below $\chi_{q}{ }^{(23),(25)}$. On the other hand, Buckmaster ${ }^{(26)}$ suggests that the extinction strain rate of the flame edge is modified to reduce the extinction value obtained by a uniformly strained counter nonpremixed flame due to the decrease in the extinction Damköhler number at the edge. This modification is also confirmed by Shay and Ronney ${ }^{(27)}$ and Noda and Tsubokura ${ }^{(28)}$. The present results may pro- vide evidence of the prediction of Buckmaster. In addition, scalar dissipation rate increases at position (a) with respect to exit velocity, whereas no large difference in pdfs exists downstream. The statistics of scalar dissipation rate indicates that the difference in turbulence in the unburned mixture for both cases is damped rapidly in the flamelet. However, this discussion does not suitably explain the extinction of the flame tip caused by the increased scalar dissipation rate for case 2 . The flame interaction and partial premixing amplified by the exit velocity should be considered as probable causes.

\section{4 Comparison to previous model}

The present data are compared to a model proposed by Müller et al. ${ }^{(1)}$, which combines the flamelet model and the scalar field variable $G$, to predict lifted turbulent nonpremixed flames. In the model, the $G$ equation is used to predict premixed flames specified by $G_{0}$, corresponding to the triple flame. The flame base structure is determined by the weighted sum of the burned flamelet and the unburned mixture as the transient flame structure from the frozen to flame regions. Flame brush, as the fluctuation of the flame tip, is approximated by the Gaussian fluctuation of $G$. For simplicity, the effect of flame stretch is represented only by the mean velocity gradient.

The nonpremixed flamelet structure at the base of the lifted flame is supposed to be modified from the counter nonpremixed flame structure, because the extinction at the flame tip occurs less extensively than the quenching scalar dissipation rate predicted by the uniformly strained counter nonpremixed flame $\chi_{q}$. The log-normal approximation for scalar dissipation rate statistics is applicable to nonpremixed flamelets at the lifted flame base, which Müller et al. did not use. If the approximation is employed in the modeling of lifted turbulent nonpremixed flames, the following equation may be used according to the conventional flamelet model to determine log-normal pdf profiles $^{(25)}$.

$$
\tilde{\chi}=c_{\chi} \frac{\tilde{\varepsilon}}{\tilde{k}} \widetilde{Z^{\prime \prime 2}}
$$

Here $\tilde{k}$ is the kinetic energy of turbulence, $\tilde{\varepsilon}$ is the dissipation rate of $\tilde{k}, \tilde{Z}^{\prime \prime 2}$ is the variance of the mixture fraction, and $c_{\chi}$ is a coefficient equal to 2 . Here, the tilde indicates the density-weighted mean. The variables $\tilde{\varepsilon}, \tilde{k}$, and $\tilde{Z}^{\prime \prime 2}$ are given as solutions of the governing equations. Equation (10) is furthermore related to the mean $\mu$ and the variance $\sigma^{2}$ of the log-normal pdf as

$$
\tilde{\chi}=\exp \left(\mu+\frac{1}{2} \sigma^{2}\right),
$$

where $\sigma^{2}$ is found to be approximately $2^{(29),(30)}$.

The present results yield a $\sigma^{2}$ between 1.15 and 2.46 at positions (b) and (c). Furthermore, we implemented a cold-fuel jet calculation for case 1 which is equivalent to the flamelet calculation using the frozen structure 


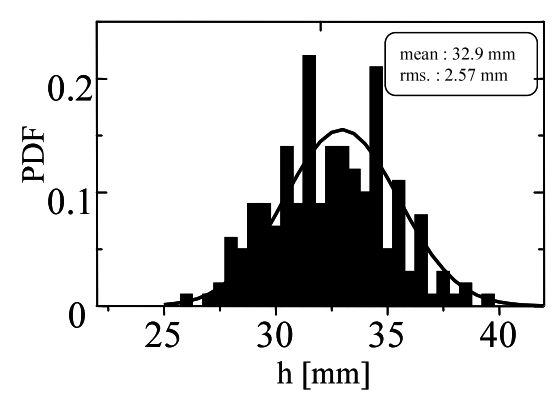

Fig. 8 Pdf of liftoff height (case 1). The solid line denotes the Gaussian profile.

to evaluate $\mu$ using Eqs. (10) and (11). The calculations yielded $\mu=-2.8$ at $x / d=10$ and $\tilde{Z}_{s t}=0.048$, corresponding to the liftoff height and the flame position, respectively, of case 1 , where $\tilde{\varepsilon}=91.7\left(\mathrm{~m}^{2} / \mathrm{s}^{2}\right) / \mathrm{s}, \tilde{k}=0.9 \mathrm{~m}^{2} / \mathrm{s}^{2}$, and $\tilde{Z}^{\prime \prime 2}=0.78 \times 10^{-3}$. This value is probably overestimated in comparison to the present data $(\mu=-5 \sim-2.8)$ at positions (a), (b), and (c), even though measurement error is taken into consideration.

The treatment of flame brush in the model of Müller et al., which is approximated by the Gaussian $G$ fluctuation, has also been examined. The variance $\overline{G^{\prime 2}}$ is assumed to be proportional to the square of the integral length scale $\ell_{t}=\tilde{k}^{3 / 2} / \tilde{\varepsilon}$. The proportionality factor is adjusted between 0.5 and 1.0, depending on the numerical grid size used to obtain stable solutions. These relationships are related to the brush width ${ }^{(31)} \ell_{F, t}$ as expressed by

$$
\ell_{F, t}=2{\overline{\left(G^{\prime 2}\right)}}^{1 / 2} \text {. }
$$

The liftoff height measured for case 1 fluctuates in a Gaussian manner, as shown in Fig. 8. The mean height is $33 \mathrm{~mm}$, and the rms value is $2.6 \mathrm{~mm}$. The brush width for case 1 is $5.2 \mathrm{~mm}$. Thus, the brush width $\ell_{F, t}$ predicted by the above equations must be compared to the measured flame brush width. The data of $\tilde{k}$ and $\tilde{\varepsilon}$ at $x / d=10$ predicted by the above calculation are again used to obtain $\ell_{F, t}$ values of $11 \mathrm{~mm}$ to $16 \mathrm{~mm}$, which are larger than the measured value by a factor of two or three. This result suggests the need to use of a low proportionality factor. The above discussion reveals that the model proposed by Müller et al. can qualitatively predict lifted turbulent nonpremixed flames, but modification is required to obtain more accurate quantitative prediction taking into account the edge flame structure, the statistics of scalar dissipation rate, and the statistics of flame brush.

\section{Conclusions}

Nonpremixed flamelet statistics at the base of lifted turbulent nonpremixed flames were investigated experimentally using a planar temperature Rayleigh scattering method. Temperature data measured by the planar Rayleigh scattering method are discussed in relation to maximum temperature at several flame positions based on the instantaneous flame base tip as containing information on the reaction region of each nonpremixed flamelet at each position. The present data are also compared to a model proposed by Müller et al. ${ }^{(1)}$, which combined the flamelet model and the scalar field variable $G$, to predict lifted turbulent nonpremixed flames. The primary results obtained are as follows.

(1) The statistics in terms of maximum temperature, thermal dissipation rate, and scalar dissipation rate are very similar at the bases of lifted flames, with slight differences at the flame base tip. This similarity indicates that the present lifted nonpremixed flames are anchored under suitable conditions for stabilization as determined by flame stretch.

(2) The scalar dissipation rates of nonpremixed flamelets at the bases of lifted nonpremixed flames fluctuate in a log-normal manner similarly to the case of rimstabilized nonpremixed flames, and distribute less than the quenching scalar dissipation rate predicted by the uniformly strained counter nonpremixed flame. These lognormal statistics indicate that the bases of lifted turbulent nonpremixed flames are not strongly statistically affected by partial premixing. This result means that the conventional flamelet concept is applicable to nonpremixed flamelets at the bases of lifted nonpremixed flames with the modification of quenching scalar dissipation rate.

(3) Liftoff height fluctuates in a Gaussian manner and flame brush is statistically associated with the scalar field variable. Consequently, the nonpremixed flamelet statistics at the flame base are found to be rebuilt on the basis of the combination of the flamelet concept and the scalar field variable proposed by Müller et al. ${ }^{(1)}$, together with consideration of the edge flame structure, the statistics of scalar dissipation rate, and the statistics of flame brush.

\section{References}

( 1 ) Müller, C.M., Breitbach, H. and Peters, N., Partially Premixed Turbulent Flame Propagation in Jet Flames, Proc. Comb. Inst., Vol.25 (1994), pp.1099-1106.

(2) Vanquickenbone, L. and Van Tiggelen, A., The Stabilization Mechanism of Lifted Diffusion Flames, Combust. Flame, Vol.10 (1966), pp.59-69.

( 3 ) Pitts, W.M., Assessment of Theories for the Behavior and Blowout of Lifted Turbulent Jet Diffusion Flames, Proc. Comb. Inst., Vol.22 (1988), pp.809-816.

( 4 ) Peters, N. and Williams, F.A., Liftoff Characteristics of Turbulent Jet Diffusion Flames, AIAA J., Vol.21 (1983), pp.423-429.

( 5 ) Kalghatgi, G.T., Lift-off Heights and Visible Lengths of Vertical Turbulent Jet Diffusion Flames in Still Air, Combust. Sci. Technol., Vol.41 (1984), pp.17-29.

( 6 ) Eickhoff, H., Lenze, B. and Leuckel, W., Experimental Investigation on the Stabilization Mechanism of Jet Diffusion Flames, Proc. Comb. Inst., Vol.20 (1984), pp.311-318. 
( 7 ) Schefer, R.W. and Goix, P.J., Mechanism of Flame Stabilization in Turbulent, Lifted-Jet Flames, Combust. Flame, Vol.112 (1998), pp.559-574.

( 8 ) Watson, K.A., Lyons, K.M., Donbar, J.M. and Carter, C.D., Observations on the Leading Edge in Lifted Flame Stabilization, Combust. Flame, Vol.119, No.1 (1999), pp.199-202.

( 9 ) Watson, K.A., Lyons, K.M., Donbar, J.M. and Carter, C.D., Simultaneous Rayleigh Imaging and CH-PLIF Measurements in a Lifted Jet Diffusion Flame, Combust. Flame, Vol.123 (2000), pp.252-265.

(10) Idera, M., Motoyasu, A., Morikawa, M., Noda, S. and Onuma, Y., NOx Formation in Lifted Non-Premixed Jet Flames, 37th Japanese Symp. on Combust., (in Japanese), (1999), pp.113-114.

(11) Fujimori, T., Riechelmann, D. and Sato, J., Effect of Liftoff on NOx Emission of Turbulent Jet Flame in High-Temperature Coflowing Air, Proc. Comb. Inst., Vol.27 (1998), pp.1149-1155.

(12) Fujimori, T., Hamano, Y. and Sato, J., Radiative Heat Loss and NOx Emission of Turbulent Jet Flames in Preheated Air up to $1230 \mathrm{~K}$, Proc. Comb. Inst., Vol.28 (2000), pp.455-461.

(13) Dibble, R.W. and Hollenbach, R.E., Laser Rayleigh Thermometry in Turbulent Flames, Proc. Comb. Inst., Vol.18 (1981), pp.1489-1499.

(14) Yoshikawa, N., Niwa, C. and Ohtake, K., Measurements of Flame Temperature Fluctuations Using Rayleigh Scattering Method, Trans. Jpn. Soc. Mech. Eng., (in Japanese), Vol.50, No.452, B (1983), pp.1088-1094.

(15) Namazian, M., Schefer, R.W. and Kelly, J., Scalar Dissipation Measurements in the Developing Region of a Jet, Combust. Flame, Vol.74 (1988), pp.147-160.

(16) Everest, D.A., Driscoll, J.F., Dahm, W.J.A. and Feikema, D.A., Images of the Two-Dimensional Field and Temperature Gradients to Quantify Mixing Rates within a Non-Premixed Turbulent Jet Flame, Combust. Flame, Vol.101 (1995), pp.58-68.

(17) Watson, K.A., Lyons, K.M., Donbar, J.M. and Carter, C.D., On Scalar Dissipation and Partially Premixed Flame Propagation, Combust. Sci. Technol., Vol.175 (2003), pp.649-664.

(18) Turns, S.R., An Introduction to Combustion, (2000), McGraw-Hill Companies, Inc., USA.

(19) Chelliah, H.K., Seshadri, K. and Law, C.K., Reduced
Kinetic Mechanisms for Counterflow Methane-Air Diffusion Flames, Reduced Kinetic Mechanisms for Applications in Combustion Systems, Edited by Peters, N. and Rogg, B., (1993), Springer-Verlag, Berlin, Heidelberg.

(20) Masri, A.R., Dibble, R.W. and Barlow, R.S., The Structure of Turbulent Nonpremixed Flames Revealed by Raman-Rayleigh-LIF Measurements, Prog. Energy Combust. Sci., Vol.22 (1996), pp.307-362.

(21) Yamamoto, K. and Onuma, Y., Effects of Hydrogen Addition on Lean Combustion, Trans. Jpn. Soc. Mech. Eng., (in Japanese), Vol.65, No.636, B (1999), pp.2895-2901.

(22) Buckmaster, J., Edge-Flames and Their Stability, Combust. Sci. Technol., Vol.115 (1996), pp.41-68.

(23) Peters, N., Local Quenching Due to Flame Stretch and Non-Premixed Turbulent Combustion, Combust. Sci. Technol., Vol.30 (1983), pp.1-17.

(24) Kimura, H., An Experimental Study of Counterflow Diffusion Flames Subject to Flame Stretch Gradients, Master Thesis, Toyohashi University of Technology, Toyohashi, (2002).

(25) Peters, N., Laminar Diffusion Flamelet Models in NonPremixed Turbulent Combustion, Prog. Energy Combust. Sci., Vol.10 (1984), pp.319-339.

(26) Buckmaster, J. and Weber, R., Edge-Flame-Holding, Proc. Comb. Inst., Vol.26 (1996), pp.1143-1149.

(27) Shay, M.L. and Ronney, P.D., Nonpremixed Edge Flames in Spatially Varying Straining Flows, Combust. Flame, Vol.112 (1998), pp.171-180.

(28) Noda, S. and Tsubokura, T., On Modeling of Quenching Phenomena by Numerical Data of Counterflow Diffusion Flames, Trans. Jpn. Soc. Mech. Eng., (in Japanese), Vol.68, No.667, B (2002), pp.926-934.

(29) Sreenivasan, K.R., Antonia, R.A. and Danh, H.Q., Temperature Dissipation Fluctuations in a Turbulent Boundary Layer, Physics of Fluids, Vol.20, No.10 (1977), pp.1238-1249.

(30) Massiello, P.J., Intermittency of the Fine Structure of Turbulent Velocity and Temperature Fields Measured at High Reynolds Number, Ph.D. Thesis, University of California, San Diego, (1974).

(31) Bray, K.N.C. and Peters, N., Laminar Flamelets in Turbulent Flames, Turbulent Reactive Flows, Edited by Libby, P.A. and Williams, F.A., (1994), Academic Press, New York. 